\title{
Assessment of clinical methods and ultrasound in predicting fetal birth weight in term pregnant women
}

\author{
Ruby Yadav ${ }^{1}$, Barun Kumar Sharma ${ }^{2}$, Ritu Nath Deokota ${ }^{3}$, Hafizur Rahman $^{1}$.
}

\author{
${ }^{1}$ Department of Obstetrics and Gynaecology, Sikkim Manipal Institute of Medical sciences and associated Central \\ Referral Hospital, Gangtok, Sikkim, India \\ ${ }^{2}$ Department of Radiodiagnosis, Sikkim Manipal Institute of Medical sciences and associated Central Referral \\ Hospital, Gangtok, Sikkim, India \\ ${ }^{3}$ Department of Obstetrics and Gynaecology, STNM Hospital, Gangtok, Sikkim, India
}

Received: 21 June 2016

Accepted: 09 July 2016

\section{*Correspondence:}

Dr. Hafizur Rahman,

E-mail: hafizezzy@gmail.com

Copyright: ( ) the author(s), publisher and licensee Medip Academy. This is an open-access article distributed under the terms of the Creative Commons Attribution Non-Commercial License, which permits unrestricted non-commercial use, distribution, and reproduction in any medium, provided the original work is properly cited.

\section{ABSTRACT}

Background: Birth weight is the greatest single factor in the survival of fetus and important factor of neonatal problems. Thus estimating fetal weight antenatally is important to the obstetricians to prevent respiratory morbidity and anticipate problems of shoulder dystocia. The objectives of this study were to assess the fetal weight in term pregnancies by various clinical methods and Ultrasound and to correlate these methods of estimation of fetal weight with the actual birth weight of the baby after delivery.

Methods: Between January 2013 to June 2014 a prospective cross-sectional hospital based study was conducted at the Department of Obstetrics and Gynaecology of Central Referral Hospital, Sikkim Manipal Institute of Medical Sciences Gangtok. All subjects with singleton pregnancy with reliable date/dating scan, with no fetal anomalies, undergoing obstetric scan at term one week prior to delivery were included. Estimated fetal weight (EFW) was calculated by clinical method $\mathrm{AG} \times \mathrm{SFH}$ (Abdominal girth $\mathrm{x}$ Symphysiofundal height) and Johnson's formula. Hadlock formula using Ultrasound was used. EFW were compared with the actual birth weight.

Results: Two hundred women were recruited during the study period. Mean age of the women were $25.24 \pm 3.32$ years and mean gestational age was $38.83 \pm 1.10$ weeks. For all the cases scan delivery interval was less than seven days. Sixty nine percent of birth weights were distributed between 2000-3500 grams. Mean birth weight of Hadlock's formula (3240 grams) was closest to the mean of actual birth weight (3100 grams). Hadlock Formula was more accurate for birth range between 2500-3500 grams followed by AG×SFH. For Large for Gestational age babies Johnson's Formula was found to be better. Average error in estimating fetal weight was 190.34 grams by Hadlock's formula, 208.78 grams by AG x SFH and 290.29 grams by Johnson's method. The difference between Hadlock's and AG $\times$ SFH was not statistically significant $(p>0.01)$; but for Johnson's it was statistically significant $(p<0.01)$. Prediction of birth weight within $10 \%$ of actual birth weight was in $81 \%$ of Cases by AG x SFH formula, $79 \%$ by Hadlock's formula, and 47\% by Johnson's formula.

Conclusions: Clinical estimation of birth weight clearly has a role in management of labour and delivery in a term pregnancy. Clinical estimation especially by $\mathrm{SFH} \times \mathrm{AG}$ method is as accurate as routine USG estimated in average birth weight. SFH $\times$ AG clinical formula can be of great value in developing countries like ours, where ultrasound is not available at many health care centers especially in a rural area.

Keywords: Abdominal girth, Symphysiofundal height, Fetal weight, Hadlock formula, Ultrasound 


\section{INTRODUCTION}

Fetal weight in conjunction with gestational age is an important indicator of pregnancy outcome. ${ }^{1}$ Birth weight is the greatest single factor in the survival of fetus and important factor of neonatal problems. ${ }^{2}$ Extremes of birth weight are associated with an increased risk of newborn complications during labour and puerperium. ${ }^{3}$ Accurate estimation of fetal weight helps in decision making in preterm fetus, small for gestational age (SGA) fetus, fetal growth restriction (FGR), preterm premature rupture of membranes, large for gestational age (LGA) fetus, macrosomic fetus, previous cesarean sections where the time and the route of delivery needs to be planned in advance. Thus estimating fetal weight antenatally is important to the obstetricians to prevent respiratory morbidity and anticipate problems of shoulder dystocia to reduce the risk of mortality and morbidity to mother and neonate. ${ }^{4}$ The main difficulty in assessing fetal weight is inaccessibility of fetus to outside world. ${ }^{5}$ Accurate estimation of fetal weight would help in successful management of labour and care of the newborn in the neonatal period and prevent complications associated with fetal macrosomia and low-birth weight babies, thereby decreasing perinatal morbidity and mortality. ${ }^{6-7}$ The available techniques for fetal weight estimation are clinical methods and ultrasonography (USG). Some investigators consider sonographic estimates to be superior to clinical estimates; others confer similar level of accuracy. Several studies indicate that physician conducted physical examination of pregnant women and estimated fetal weights are superior to ultrasonic fetal measurement. $^{8-9}$

All currently-available techniques for estimating fetal weight have significant degree of inaccuracy, and various studies have been done to compare the accuracy of different methods of estimation. The potential complications associated with birth of both small and excessively large fetuses requires that accurate estimation of fetal weight occurs in advance of deliveries. ${ }^{10}$ The objective of this study was to assess the fetal weight in term pregnancies by clinical methods and by ultrasound using Hadlock's formula and to assess the accuracy of these methods when compared to neonatal weight.

\section{METHODS}

It was a prospective cross-sectional hospital based study conducted at Central Referral Hospital (CRH) which is a teaching hospital of Sikkim Manipal Institute of Medical Sciences (SMIMS). The study was conducted over duration of eighteen months between January 2013 and June 2014. Two hundred and eleven women were recruited for the study, but only 200 completed the study. These patients who were selected from antenatal clinics and maternity wards had their last fetal weight estimation done within one week of delivery. The study was approved by SMIMS institutional ethics committee.
Detailed obstetric and menstrual history was taken. The duration of gestation was calculated according to Naegle's rule or by first trimester scan report. Patients in whom delivery was anticipated within one week were included in this study; and those who did not deliver within one week of fetal weight estimation were excluded from the study. Fetal weight was estimated by clinical methods and by ultrasound.

\section{Fetal weight estimation by clinical methods}

EFW (Wt in Grams) = AG (cms) x SFH (cms) (Insler's Formula)

After emptying the bladder, patient was in supine position with legs flat on the bed. Abdominal girth was measured at the level of umbilicus and expressed in centimetres. After correction of dextro-rotation, Mc Donald's measurement of height of the fundus from upper edge of symphysis pubis following the curvature of abdomen were taken in inch initially to prevent observer bias and then expressed in centimetres. The upper hand was placed firmly against the top of the fundus, with the measuring tape pressing between the index and middle fingers; readings were taken from perpendicular intersection of the tape with the fingers.

\section{Fetal weight estimation by simplified Johnson's formula}

McDonald's measurement of Symphysiofundal height is done. Station of presenting part was assessed by abdominal examination and by vaginal examination. Fetal weight was estimated as follows: Fetal weights $($ Grams $)=($ McDonald's measurement -13$) \times 155$. When the presenting part was at 'minus' station

$=($ McDonald's measurement -12$) \times 155$, when presenting part was at 'zero' station.

$=($ McDonald's measurement -11$) \times 155$ when presenting part was at plus station.

\section{Fetal weight estimation by Hadlock's formula using ultrasonography}

Sonographic examination was done in all patients using $3.5 \mathrm{MHz}$ convex assay and linear assay transverse (LOGIQ model with M \& B mode for simultaneous imaging and calculating fetal heart rate). After biparietal diameter (BPD) abdominal circumference (AC) and femur length (FL) were measured in centimetres, the sonography machine calculated fetal weight by formula. $\log 10(\mathrm{EFW})=1.4787-0.003343 \mathrm{AC} \times \mathrm{FL}+0.001837$ BPD2 + 0.0458 AC + 0.158FL.

Predicted estimated fetal weight by each method was compared with respective neonatal actual birth weight using electronic machine in central referral hospital which showed the accurate birth weight. 


\section{RESULTS}

A total of two hundred consecutive women were studied. Most of the women were between 21-30 years of age $(85 \%)$ and primigravida (59\%). Fifty two percent patients had normal vaginal delivery and rest had cesarean delivery. Table 1 represents the patient profiles of the studied women.

Table 1: Patient profile of the studied women.

\begin{tabular}{|c|c|c|}
\hline Characteristics & Number (n) & $\%$ \\
\hline \multicolumn{3}{|l|}{ Age (in years) } \\
\hline$<20$ & 19 & 9.50 \\
\hline $21-25$ & 91 & 45.50 \\
\hline $26-30$ & 81 & 40.50 \\
\hline $31-35$ & 9 & 4.50 \\
\hline \multicolumn{3}{|l|}{ Parity } \\
\hline Primigravida & 118 & 59 \\
\hline Multigravida & 82 & 41 \\
\hline \multicolumn{3}{|l|}{ Gestational age } \\
\hline 37-38 weeks & 52 & 26 \\
\hline 38.1-39 weeks & 54 & 27 \\
\hline 39.1-40 weeks & 74 & 37 \\
\hline 40.1-42 weeks & 20 & 10 \\
\hline \multicolumn{3}{|c|}{ Symphysis fundal height (in cm) } \\
\hline $25-30$ & 32 & 16 \\
\hline $30.1-35$ & 95 & 47.5 \\
\hline $35.1-40$ & 73 & 36.5 \\
\hline \multicolumn{3}{|l|}{ Mode of delivery } \\
\hline NVD & 105 & 52.5 \\
\hline LSCS & 95 & 47.5 \\
\hline
\end{tabular}

NVD-Normal Vaginal Delivery, LSCS-Lower segment cesarean section

Post-delivery, the actual birth weight of babies was between the 2000 Grams to 4300 Grams (Table 2). Mean birth weight was $3100 \pm 455.8$ Grams. Maximum $(35.5 \%)$ babies were in range of 2501 -3000 gram, followed by 3001-3500 grams (33.4\%).

The mean actual birth weight was $3100 \pm 455.8$ grams. The mean estimated birth weight by $\mathrm{AG} \times \mathrm{SFH}$ was $2971 \pm 337.9$ grams and mean estimated birth weight by USG was $3240 \pm 389.7$ grams while the mean estimated birth weight by Johnson's formula was $2911 \pm 364$ grams. The mean difference of birth weight by different method from actual is depicted in Table 3. Clinically this much mean difference might not be significant but statistically it was significant. Mean difference was least in USG followed by $\mathrm{AG} \times \mathrm{SFH}$.

The average and maximum error was highest by Johnson's formula, while both type of error was least with USG (Hadlock's) formula. When considered individual age groups average error was maximum in weight group 3500-4000 grams by all Formulae while maximum error was highest in the weight group 30003500 grams (Table 4).

Table 2: Actual birth weight of the babies after delivery.

\begin{tabular}{|lll|}
\hline Birth weight in Grams & Number (n) & $\%$ \\
\hline $2000-2500$ & 23 & 11.5 \\
\hline $2501-3000$ & 71 & 35.5 \\
\hline $3001-3500$ & 67 & 33.5 \\
\hline $3501-4000$ & 34 & 17.0 \\
\hline $4001-4500$ & 5 & 2.5 \\
\hline
\end{tabular}

Using AG x SFH formula prediction of birth weight in $81 \%$ of cases was within $10 \%$ of actual birth weight. Using ultrasonography prediction of birth weight in $79 \%$ of cases was within $10 \%$ as compared to $47 \%$ by Johnson's formula (Table 5).

Table 3: Mean birth weight by different method and mean difference from actual birth weight.

\begin{tabular}{|lllll|}
\hline Method & $\begin{array}{l}\text { Mean } \\
\text { Weight } \pm \\
\text { SD } \\
\text { (grams) }\end{array}$ & Range & $\begin{array}{l}\text { Mean } \\
\text { difference } \\
\text { from actual } \\
\text { (grams) }\end{array}$ & $\begin{array}{l}\text { P } \\
\text { value }\end{array}$ \\
\hline $\begin{array}{l}\text { Actual } \\
\text { birth } \\
\text { weight }\end{array}$ & $\begin{array}{l}3100 \pm \\
455.8\end{array}$ & $\begin{array}{l}2000- \\
4300\end{array}$ & - \\
\hline AG $\times$ SFH & $\begin{array}{l}2971 \pm \\
337.9\end{array}$ & $\begin{array}{l}2100- \\
4200\end{array}$ & 119 Grams & $<0.01$ \\
\hline USG & $\begin{array}{l}3240 \pm \\
389.7\end{array}$ & $\begin{array}{l}2105- \\
4050\end{array}$ & 140 Grams & $<0.01$ \\
\hline Johnson's & $\begin{array}{l}2911 \pm \\
364.0\end{array}$ & $\begin{array}{l}1950- \\
3820\end{array}$ & 189 Grams & $<0.01$ \\
\hline
\end{tabular}

$\mathrm{AG} \times \mathrm{SFH}=$ abdominal girth $\mathrm{X}$ Symphysiofundal height, USGUltrasonography

Results of the correlation analysis showed that there is a significant relationship between estimated and actual birth weights for all the methods. This relationship was used to predict the actual birth weight by using estimated fetal weight. The standard deviation indicates how much variation can be expected in the predicted birth weight by each method. Least variation was found in AG x SFH ( \pm 240.9 grams) followed by USG $( \pm 251.3$ grams $)$ and highest variation in Johnson's Formula (Table 6).

\section{DISCUSSION}

Accurate estimation of fetal weight is of paramount importance in the management of labour and delivery. During last decade, estimated fetal weight has been incorporated into the standard routine ante-partum evaluation of high risk pregnancies and deliveries. A lot of work has been done to find out accurate methods of estimation of fetal size and weight in utero. They include clinical and ultrasound estimations. Equipped with information about the weight of fetus, the obstetrician managing labour is able to pursue sound obstetric 
management decreasing perinatal morbidity and mortality. 9,10

In Present Study the mean birth weight of $\mathrm{AG} \times \mathrm{SFH}$ Formula (2971 \pm 337.9 grams) was closest to the mean of actual birth weight $(3100 \pm 455.8$ grams $)$ in compared with Hadlock's Formula $(3240 \pm 389.7$ grams $)$ and
Johnson's formula (2911 \pm 364 grams). Similar observations were reported by Chauhan et al. ${ }^{11}$ The $p$ value obtained for the mean birth weight of $\mathrm{AG} \times \mathrm{SFH}$ Formula, Hadlock formula and Johnson's formula is $<0.01$. This indicates that formulae are highly significant in obtaining the mean birth weight but not when taken individually.

Table 4: Average and maximum error of birth weight by various methods.

\begin{tabular}{|c|c|c|c|c|c|c|c|c|c|c|c|c|}
\hline $\begin{array}{l}\text { Birth } \\
\text { weight } \\
\text { gm }\end{array}$ & \multicolumn{2}{|c|}{$\begin{array}{l}2000-2500 \\
(n=23)\end{array}$} & \multicolumn{2}{|c|}{$2501-3000(n=71)$} & \multicolumn{2}{|c|}{$3001-3500(n=67)$} & \multicolumn{2}{|c|}{$3501-4000(n=34)$} & \multicolumn{2}{|c|}{$4001-4500(n=67)$} & \multicolumn{2}{|c|}{$\begin{array}{l}\text { All cases } \\
(n=200)\end{array}$} \\
\hline Method & Avg. & Max & Avg. & Max & Avg. & Max. & Avg. & Max & Avg. & Max & Avg. & Max \\
\hline $\mathrm{AG} \times \mathrm{SFH}$ & 246 & 1030 & 190 & 994 & 183 & 910 & 199 & 834 & 225 & 810 & 208 & 986 \\
\hline USG & 301 & 904 & 168 & 874 & 163 & 753 & 177 & 734 & 142 & 874 & 190 & 845 \\
\hline Johnson's & 235 & 1335 & 359 & 1170 & 319 & 1013 & 360 & 975 & 190 & 775 & 293 & 1100 \\
\hline
\end{tabular}

AG $\times$ SFH=abdominal girth X Symphysiofundal height, USG-Ultrasonography

Table 5: Percentage error in various methods.

\begin{tabular}{|llll|}
\hline Method & AGXSFH & USG & Johnson's \\
\hline $5 \%$ & $19 \%$ & $35 \%$ & $15 \%$ \\
\hline $10 \%$ & $81 \%$ & $79 \%$ & $47 \%$ \\
\hline $15 \%$ & $98 \%$ & $93 \%$ & $93 \%$ \\
\hline $20 \%$ & $100 \%$ & $98 \%$ & $100 \%$ \\
\hline $25 \%$ & - & $100 \%$ & \\
\hline
\end{tabular}

$\mathrm{AG} \times \mathrm{SFH}=$ abdominal girth $\mathrm{X}$ Symphysiofundal height, USGUltrasonography

Table 6: Correlation co-efficient and standard deviation of prediction error.

\begin{tabular}{|lll|}
\hline Method & $\begin{array}{l}\text { Correlation co- } \\
\text { efficient }\end{array}$ & $\begin{array}{l}\text { Standard Deviation } \\
\text { (grams) }\end{array}$ \\
\hline AG $\times$ SFH & +0.75 & 240.9 \\
\hline USG & +0.73 & 251.3 \\
\hline Johnson's & +0.46 & 324.7 \\
\hline
\end{tabular}

Pearson's correlation coefficient $\mathrm{P}<0.01$, Significant; $\mathrm{AG} \times \mathrm{SFH}=$ abdominal girth $\mathrm{X}$ Symphysiofundal height, USGUltrasonography

In their study Raghuvanshi et al found average error was minimum (140 grams) with Ultrasound using Hadlock's Formula and maximum with Johnson's (454.9 grams). ${ }^{12}$ In Present study average error was also least with Ultrasound using Hadlock's Formula (190.34 grams) followed by AG×SFH Formula (208.74 grams). The error was Maximum with Johnson's Formula (290.29 grams). The mean error of the Hadlock Formula is least because Hadlock formula uses four parameters. The difference in average error between Hadlock's formula using Ultrasonography and AG $\mathrm{x}$ SFH is not statistically significant. Similarly, maximum error was also least with Hadlock's formula (845 grams) and least with Johnson's formula 1100 grams. Similar observations were made by Raghuvanshi et al. ${ }^{12}$

Sherman et al and Bhandary et al reported that rates of estimates within $10 \%$ of birth weight were not statistically significant in clinical and USG method (72\% and $69 \%$ respectively in Sherman et al and $67 \%$ and $62 \%$ respectively in Bhandary et al). ${ }^{13,14}$

In present study as well clinical estimation by AG x SFH and USG method are equally good for estimation of birth weight within $10 \%$ of birth weight and the difference is not statistically significant.

In the present study the standard deviation of prediction error was least with AG×SFH (240.9 grams) followed by Hadlock's using Ultrasound (251.3 grams) and maximum with Johnson's formula. Chauhan et al also reported that standard deviation of prediction error was least with Hadlock's (258.8grams) followed with $\mathrm{AG} \times \mathrm{SFH}$. $^{11}$

We also studied the effect of fetal weight in the mode of delivery. As there were other factors involved, such as fetal distress, previous LSCS, EFW alone did not affect the mode of delivery. More than half of the patients $(57.5 \%)$ had delivered vaginally and rate of cesarean delivery $(47.5 \%)$ was high may be because ours is a tertiary referral hospital.

Our study had some limitations. All foetuses tend to gain some weight in utero from the day of scan till date of delivery. In our study correction for weight gain is not made. As present study was done in the teaching institution and different scans are done by different radiologists, hence there might be inter -observer errors. 


\section{CONCLUSION}

Clinical estimation of birth weight clearly has a role in management of labour and delivery in a term pregnancy. Of the two clinical formula's studied, AG $x$ SFH has better predictable results in fetal weight estimation, compared to Johnson's Formula.

Clinical estimation especially by $\mathrm{SFH} \times \mathrm{AG}$ method is as accurate as routine USG estimated in average birth weight. Ultrasound require sophisticated instrument for carrying out the procedure. Hence it becomes costlier in a low resource set up. SFH $\times$ AG clinical formula can be of great value in developing countries like ours, where ultrasound is not available at many health care centres especially in a rural area. Based on this finding, combining the different methods of fetal weight prediction to improve their overall accuracy may be possible.

Funding: No funding sources

Conflict of interest: None declared

Ethical approval: The study was approved by the Institutional Ethics Committee

\section{REFERENCES}

1. Barnhard Y, Bar-Hava I, Divon MY. Accuracy of intrapartum estimates of fetal weight. Effect of oligohydramnios. J Reprod Med. 1996;41(12):90710 .

2. Raman S, Urquhart R, Yusof M. Clinical versus ultrasound estimation of fetal weight. Aust N Z J Obstet Gynaecol. 1992;32(3):196-9.

3. Jolly MC, Sebire NJ, Harris JP, Regan L, Robinson S. Risk factors for macrosomia and its clinical consequences: a study of 350,311 pregnancies. Eur J Obstet Gynecol Reprod Biol. 2003;10:111(1):9-14.

4. Nahum G. Estimation of fetal weight-a review article last updated on 11 July 2002 (http://www.emedicine.com) as accessed on 22 January 2016.
5. Sirohiwal D, Singal SR, Passi V, Sen J. Estimation of fetal weight. Obstet Gynaecol Today. 2004;9:2479.

6. Mehdizadeh A, Alaghehbandan R, Horsan $\mathrm{H}$. Comparison of clinical versus ultrasound estimation of fetal weight. Am J Perinatol. 2000;17(5):233-6.

7. Wilcox AJ, Skjaerven R. Birth weight and perinatal mortality: the effect of gestational age. Am J Public Health. 1992;82(3):378-82.

8. Ratanasiri T, Jirapornkul S, Somboonporn W, Seejorn K, Patumnakul P. Comparison of the accuracy of ultrasonic fetal weight estimation by using the various equations. J Med Assoc Thai. 2002;85(9):962-7.

9. Baum JD, Gussman D, Wirth JC. Clinical and patient estimation of fetal weight vs. ultrasound estimation. J Reprod Med. 2002;47(3):194-8.

10. Hendrix NW, Grady CS, Chauhan SP. Clinical vs. sonographic estimate of birth weight in term parturients. A randomized clinical trial. J Reprod Med. 2000;45(4):317-22.

11. Chauhan KP, Patel UJ. Comparative study of various methods of fetal weight estimation at term pregnancy. The Journal of Integrated Health Sciences. 2013;1(1):3-6.

12. Raghuvanshi T, Pawar M. Comparative Study of Fetal Weight Estimation by Various Methods among Term Pregnancies at Rural Tertiary Care Centre, Maharashtra. Journal of Evolution of Medical and Dental Sciences. 2014;3(41):10291-6.

13. Sherman DJ. A comparison of clinical and ultrasonic estimation of fetal weight. Obstetrics and gynecology. 1998;91:212-7.

14. Bhandary Amritha A, Pinto Patrick J, Shetty Ashwin P. Comparative Study of Various Methods of Fetal Weight Estimation in Term Pregnancy. Ind $\mathbf{J}$ Gynecol Obstet. 2004;54:336-9.

Cite this article as: Yadav R, Sharma BK, Deokota RN, Rahman H. Assessment of clinical methods and ultrasound in predicting fetal birth weight in term pregnant women. Int J Reprod Contracept Obstet Gynecol 2016;5:2775-9. 